Article

\title{
Bacillus subtilis PS-216 Antagonistic Activities against Campylobacter jejuni NCTC 11168 Are Modulated by Temperature, Oxygen, and Growth Medium
}

\author{
Katarina Šimunović ${ }^{1,2}$, Polonca Stefanic ${ }^{2}$, Anja Klančnik ${ }^{1} \mathbb{D}$, Andi Erega ${ }^{1,2}$, Ines Mandic Mulec ${ }^{2} \mathbb{D}$ \\ and Sonja Smole Možina ${ }^{1, *(\mathbb{D})}$ \\ 1 Chair of Biotechnology, Microbiology, and Food Safety, Department of Food Science and Technology, \\ Biotechnical Faculty, University of Ljubljana, 1000 Ljubljana, Slovenia; katarina.simunovic@bf.uni-lj.si (K.Š.); \\ anja.klancnik@bf.uni-lj.si (A.K.); andi.erega@bf.uni-lj.si (A.E.) \\ 2 Chair of Microbial Ecology and Physiology, Department of Microbiology, Biotechnical Faculty, University of \\ Ljubljana, 1000 Ljubljana, Slovenia; Polonca.Stefanic@bf.uni-lj.si (P.S.); ines.mandicmulec@bf.uni-lj.si (I.M.M.) \\ * Correspondence: Sonja.smole-mozina@bf.uni-lj.si
}

check for

updates

Citation: Šimunović, K.; Stefanic, P.; Klančnik, A.; Erega, A.; Mandic

Mulec, I.; Smole Možina, S. Bacillus subtilis PS-216 Antagonistic Activities against Campylobacter jejuni NCTC 11168 Are Modulated by Temperature, Oxygen, and Growth Medium. Microorganisms 2022, 10, 289. https://doi.org/10.3390/ microorganisms10020289

Academic Editor: Sophie Kathariou

Received: 20 December 2021

Accepted: 21 January 2022

Published: 26 January 2022

Publisher's Note: MDPI stays neutral with regard to jurisdictional claims in published maps and institutional affiliations.

Copyright: (c) 2022 by the authors. Licensee MDPI, Basel, Switzerland. This article is an open access article distributed under the terms and conditions of the Creative Commons Attribution (CC BY) license (https:// creativecommons.org/licenses/by/ $4.0 /)$.

\begin{abstract}
As the incidence of Campylobacter jejuni and campylobacteriosis grows, so does the need for a better understanding and control of this pathogen. We studied the interactions of $C$. jejuni NCTC 11168 and a potential probiotic, Bacillus subtilis PS-216, in cocultures at different starting ratios and temperatures $\left(20^{\circ} \mathrm{C}, 37^{\circ} \mathrm{C}, 42^{\circ} \mathrm{C}\right)$, under different atmospheres (aerobic, microaerobic), and in different growth media (Mueller-Hinton, chicken litter medium, chicken intestinal-content medium). Under microaerobic conditions, B. subtilis effectively inhibited the growth of $C$. jejuni at $42{ }^{\circ} \mathrm{C}(\log$ reduction, 4.19), even when $C$. jejuni counts surpassed B. subtilis by 1000 -fold in the starting inoculum. This inhibition was weaker at $37^{\circ} \mathrm{C}(\log$ reduction, 1.63), while no impact on CFUs was noted at $20^{\circ} \mathrm{C}$, which is a temperature nonpermissive of $C$. jejuni growth. Under aerobic conditions, B. subtilis supported C. jejuni survival. B. subtilis PS-216 inhibited the growth of $C$. jejuni in sterile chicken litter (4.07 log reduction) and in sterile intestinal content (2.26 log reduction). In nonsterile intestinal content, B. subtilis PS-216 was able to grow, to a lesser extent, compared to Mueller-Hinton media, still showing potential as a chicken probiotic that could be integrated into the chicken intestinal microbiota. This study showed the strong influence of environmental parameters on the variability of C. jejuni and B. subtilis interactions. Furthermore, B. subtilis PS-216 antagonism was strongest against C. jejuni NCTC 11168 under conditions that might represent conditions in the chicken environment $\left(42{ }^{\circ} \mathrm{C}\right.$, microaerobic atmosphere, chicken litter medium).
\end{abstract}

Keywords: Campylobacter jejuni; Bacillus subtilis PS-216; bacterial interaction; C. jejuni reduction; chicken intestinal content; chicken litter medium

\section{Introduction}

Campylobacter jejuni is a major cause of the most commonly reported bacterial gastroenteritis, campylobacteriosis, and it is considered a serious food safety hazard [1]. Campylobacteriosis manifests as acute watery diarrhea, fever, and cramps [2-4]. C. jejuni is a burden on both health and the economy, as the cost of campylobacteriosis and its consequences, estimated by EFSA on the basis of disability-adjusted life years per year, reaches EUR2.4 billion/year [1,5]. There is, thus, the need for better and more effective control measures.

Infection with C. jejuni is highly associated with undercooked poultry, as this pathogen is a commensal in the poultry gut [1,2]. Indeed, reduction of Campylobacter spp. by $3 \log _{10}$ units in the chicken cecum at slaughter can reduce the public health risk by up to $90 \%$, and therefore, great efforts are being made to reduce Campylobacter spp. in poultry production [5-7]. 
As part of the avian gut microbiota, C. jejuni is exposed to interactions with other inhabitants of the gut, which can either compete for nutrients and place, or cooperate, and thus ensure mutual benefit. Competition, rather than cooperation, is more common amongst different bacterial species [8], and the evidence suggests that when a nonpathogenic strain is introduced into the niche of a pathogenic C. jejuni strain, it might outcompete it, and thus remove it from that niche [9]. This concept is known as competitive exclusion, and it is often exploited using novel probiotic species or strains with the potential to control pathogens, such as C. jejuni $[10,11]$. As the primary niche of $C$. jejuni is the avian gut, efforts are focused on the reduction of this pathogen in this important source.

Probiotics have been shown to aid in the reduction of $C$. jejuni in broiler chickens, and bacteria isolated from the chicken gut are often investigated for this purpose, including Lactobacillus and Bacillus spp. [12-15]. Different Bacillus subtilis strains have been studied for the reduction of $C$. jejuni in poultry production, with promising results, and with this effect being strain specific, as not all B. subtilis can reduce C. jejuni levels [13]. B. subtilis strains as feed supplements can modify the chicken gut microbiota, and the average chicken body weight and gut health $[15,16]$. B. subtilis has the potential to produce different antibacterial substances, which might be one of the mechanisms they use against pathogenic bacteria [17-19].

Bacterial interactions are complex, even in a two-species system [20], and environmental parameters affect these interactions, such as temperature and oxygen. In a previous study, we reported that $B$. subtilis PS-216 shows antagonism towards C. jejuni in the form of growth inhibition and biofilm reduction, and that this is mediated by the antimicrobial compound bacillaene [21]. Thus, we saw it as pertinent to consider their interactions under different environmental conditions, to better understand the span of activity of this potential probiotic.

Oxygen is a key parameter that can limit $C$. jejuni growth and survival in any environment, as C. jejuni requires $2 \%$ to $10 \%$ oxygen for growth, although it is sensitive to higher oxygen concentrations [22]. Although higher oxygen environments within the farm and slaughter house environments are toxic for $C$. jejuni survival, this pathogen can still persist as part of a consortium where it is protected by other species that deplete the oxygen in the environment, thus supporting the spread of C. jejuni [23-25]. On the other hand, although B. subtilis has been considered to be a strict aerobe in the past, native B. subtilis strains can grow under oxygen limitation by using nitrate or nitrite as a terminal electron acceptor, or by fermentation (for reviews, see [26,27]). Thus, we hypothesized that the interactions of C. jejuni and B. subtilis might be relevant in an environment with oxygen limitation, such as the animal gut, and in oxygenated environments (e.g., feathers and other surfaces of the animals colonized with $C$. jejuni, in the farm water supply, on surfaces in the slaughter house surfaces, and other environments) where interactions with Bacillus strains might even be beneficial for this pathogen.

Temperature is another key ecological factor that modulates bacterial growth. C. jejuni grows best at $42{ }^{\circ} \mathrm{C}$, although metabolic activity in the form of ATP generation, protein synthesis, and oxygen consumption can be detected at temperatures as low as $4{ }^{\circ} \mathrm{C}$; however, C. jejuni shows no active growth at $<32{ }^{\circ} \mathrm{C}$ [28]. The growth of $B$. subtilis can be detected from $4{ }^{\circ} \mathrm{C}$ to $55^{\circ} \mathrm{C}$, although the optimal temperature is dependent on the strain $[29,30]$. Moreover, temperature can affect the production of antimicrobial compounds [31,32], which might have consequences for antagonism of $B$. subtilis against other species, including pathogens. C. jejuni is a fastidious microorganism that shows many limitations to its growth, including growth in a microaerobic atmosphere (i.e., limited oxygen), at limited growth temperatures $\left(32-45^{\circ} \mathrm{C}\right)$, and its inability to use glucose and other similar sugars as a carbon source $[22,28]$. B. subtilis is more flexible in terms of its growth requirements, although it is not known whether $B$. subtilis antagonizes $C$. jejuni under conditions that do not support $C$. jejuni growth (e.g., $20^{\circ} \mathrm{C}$ ). Although the interactions of these two species are likely to occur in many environments, the information on how changed environmental conditions will affect these interactions is limited. 
To evaluate B. subtilis PS-216 as a probiotic against $C$. jejuni in the chicken host, we first explored and defined their cocultivation dynamics at $42{ }^{\circ} \mathrm{C}, 37^{\circ} \mathrm{C}$, and $20^{\circ} \mathrm{C}$, under microaerobic versus aerobic conditions, and in the more complex media of chicken litter and chicken intestinal content, which represent environments that are closer to the conditions in the chicken gut. We show that $B$. subtilis acts antagonistically against $C$. jejuni at the higher temperatures, under microaerobic conditions, and in the complex media, but is protective under otherwise unfavorable conditions for $C$. jejuni at reduced temperatures and under aerobic conditions. These data also suggest that the complex media introduced here represent a model for initial evaluation of bacterial interactions in the chicken gut.

\section{Materials and Methods}

\subsection{Strains and Growth Conditions}

All cultures were stored at $-80{ }^{\circ} \mathrm{C}$ in Mueller-Hinton broth (MHB; Oxoid, UK) with $20 \%$ glycerol. From frozen stock solutions, C. jejuni NCTC 11168 was incubated on Karmali agar (Oxoid, UK) supplemented with Karmali selective supplement (SR0502; Oxoid, UK) for $24 \mathrm{~h}$ at $42{ }^{\circ} \mathrm{C}$ under microaerobic conditions $\left(5 \% \mathrm{O}_{2}, 10 \% \mathrm{CO}_{2}, 85 \% \mathrm{~N}_{2}\right)$. The microaerobic atmosphere was obtained by flushing the containers for the anaerobic incubation of samples (anaerojar) with the appropriate gas mixture just before the start of the incubations. B. subtilis PS-216 was originally isolated from riverbank soil of the Sava River in Slovenia [33], and was grown here on Mueller-Hinton agar (MHA; Oxoid, UK) at $37^{\circ} \mathrm{C}$ under aerobic conditions for $24 \mathrm{~h}$.

For cocultivation experiments, C. jejuni NCTC 11168 was further transferred onto MHA (second subculture) and incubated at $42{ }^{\circ} \mathrm{C}$ under microaerobic conditions for $24 \mathrm{~h}$. B. subtilis PS-216 was further transferred onto MHA and incubated at $37^{\circ} \mathrm{C}$ under aerobic conditions (second subculture) for $24 \mathrm{~h}$. From the second subculture of the $C$. jejuni NCTC 11168 and B. subtilis PS-216, cultures with $\mathrm{OD}_{600} 0.1$ (approx. $5 \times 10^{7} \mathrm{CFU} / \mathrm{mL}$ and $5 \times 10^{6} \mathrm{CFU} / \mathrm{mL}$, respectively) were prepared in MHB and used as the inoculum in all of the experiments.

Campylobacter jejuni was enumerated on Karmali agar supplemented with Karmali selective supplement after $24 \mathrm{~h}$ of incubation at $42{ }^{\circ} \mathrm{C}$ under microaerobic conditions. B. subtilis was enumerated on MHA after $24 \mathrm{~h}$ of incubation at $37^{\circ} \mathrm{C}$ under aerobic conditions. Bacillus spp. from fecal samples were enumerated on HiChrom Bacillus agar (Himedia, USA). To enumerate the B. subtilis spores, a protocol by Štefanič and MandičMulec (2009) [33] was used, with some modifications. Specifically, $1.0 \mathrm{~mL}$ samples were transferred from the experimental cultures into epitubes and incubated at $80^{\circ} \mathrm{C}$ for $30 \mathrm{~min}$ in a water bath, then left to cool down at room temperature. The samples were then serially diluted in phosphate-buffered saline, and plated onto HiChrom Bacillus agar. The number of vegetative cells in the samples was determined by subtracting the number of spores from the untreated samples.

\subsection{Cocultivation of B. subtilis with C. jejuni in Mueller-Hinton Broth at Different Starting Ratios}

Bacillus subtilis PS-216 was cultivated with C. jejuni NCTC 11168 at starting ratios (B. subtilis:C. jejuni) of 10:1 (approx. $10^{4} \mathrm{CFU} / \mathrm{mL}: 10^{3} \mathrm{CFU} / \mathrm{mL}$ ), 1:10 (approx. $10^{2} \mathrm{CFU} / \mathrm{mL}$ : $10^{3} \mathrm{CFU} / \mathrm{mL}$ ), 1:100 (approx. $10^{4} \mathrm{CFU} / \mathrm{mL}: 10^{6} \mathrm{CFU} / \mathrm{mL}$ ), and 1:10,000 (approx. $10^{2} \mathrm{CFU} / \mathrm{mL}$ : $10^{6} \mathrm{CFU} / \mathrm{mL}$ ) at $42{ }^{\circ} \mathrm{C}$ under microaerobic conditions in MHB (Oxoid, UK) for $48 \mathrm{~h}$. The cultures were prepared from $\mathrm{OD}_{600} 0.1$ inocula and the numbers of each of the strains were determined as CFU / $\mathrm{mL}$ at the start $(\mathrm{t}=0 \mathrm{~h})$, and at the sampling times of $4,8,12,24$, and $48 \mathrm{~h}$. As controls, B. subtilis and C. jejuni monocultures were prepared at the same starting concentrations as in the cocultures. Three independent experiments were carried out, with up to three technical replicates, and the data are shown as means \pm standard deviation. 


\subsection{Cocultivation of B. subtilis with C. jejuni in Mueller-Hinton Broth at Different Temperatures}

The effects of different temperatures on the growth dynamics of B. subtilis PS-216 and C. jejuni NCTC 11168 in cocultures were tested at $42^{\circ} \mathrm{C}, 37^{\circ} \mathrm{C}$, and $20^{\circ} \mathrm{C}$ under microaerobic conditions for $48 \mathrm{~h}$. The cultures were prepared at 1:10 starting ratios in $\mathrm{MHB}$, as approx. $10^{4} \mathrm{CFU} / \mathrm{mL}: 10^{5} \mathrm{CFU} / \mathrm{mL}$ for $42^{\circ} \mathrm{C}$ and $37^{\circ} \mathrm{C}$, and approx. $10^{5} \mathrm{CFU} / \mathrm{mL}: 10^{6} \mathrm{CFU} / \mathrm{mL}$ for $20^{\circ} \mathrm{C}$ (B. subtilis:C. jejuni). The concentrations of the bacterial cells were determined at the beginning $(\mathrm{t}=0 \mathrm{~h})$, and after 4,24 , and $48 \mathrm{~h}$ of incubation under microaerobic conditions, by disturbed sampling. Three independent experiments were carried out, with up to three technical replicates, and the data are shown as means \pm standard deviation.

\subsection{Cocultivation of B. subtilis with C. jejuni in Mueller-Hinton Broth under Aerobic Conditions}

The effects of oxygen on the dynamics of the cocultures were tested by cultivation of B. subtilis PS-216 and C. jejuni NCTC 11168 under aerobic conditions at $37^{\circ} \mathrm{C}$ and $20^{\circ} \mathrm{C}$ for $48 \mathrm{~h}$. The cultures were prepared at 1:10 starting ratios in MHB (B. subtilis:C. jejuni; approx. $10^{4} \mathrm{CFU} / \mathrm{mL}: 10^{5} \mathrm{CFU} / \mathrm{mL}$ for $37^{\circ} \mathrm{C}$, and approx. $10^{5} \mathrm{CFU} / \mathrm{mL}: 10^{6} \mathrm{CFU} / \mathrm{mL}$ for $20^{\circ} \mathrm{C}$ ). The concentrations of the bacterial cells were determined at the beginning $(\mathrm{t}=0 \mathrm{~h})$, and after 4,24 , and $48 \mathrm{~h}$ of incubation, by disturbed sampling. Three independent experiments were carried out, with up to three technical replicates, and the data are shown as means \pm standard deviation.

\subsection{Cocultivation of B. subtilis PS-216 and C. jejuni NCTC 11168 in Broiler Chicken Intestinal Content Medium}

Bacillus subtilis PS-216 and C. jejuni NCTC 11168 were cultivated in two sterile broiler chicken feces media models: (i) a sterile litter medium; and (ii) a sterile intestinal-content medium. The starting ratio was 1:100 (B. subtilis:C. jejuni; approx. $10^{3} \mathrm{CFU} / \mathrm{mL}: 10^{5} \mathrm{CFU} / \mathrm{mL}$ ), with incubation at $42{ }^{\circ} \mathrm{C}$ under microaerobic conditions for $48 \mathrm{~h}$.

The broiler chicken litter medium was prepared from broiler chicken litter collected from a commercial farm (Perutnina Ptuj d.d., Slovenia), which was suspended in phosphatebuffered saline (Oxoid, UK) at a ratio of 1:9 (w/v), and then autoclaved $\left(121^{\circ} \mathrm{C}, 15 \mathrm{~min}\right)$. For the broiler chicken intestinal-content medium, the intestinal contents (small and large intestines combined) from 14 broiler chickens from one flock of 49-day-old broilers from a semi-intensive rearing system (fed with bro-starter and bro-finisher obtained from Jata Emona d.o.o., Slovenia), were collected, pooled, and stored at $-80^{\circ} \mathrm{C}$. For these cultivation experiments, the intestinal content was diluted in phosphate-buffered saline at a ratio of 1:1 $(v / v)$ and autoclaved. B. subtilis and C. jejuni monoculture positive controls were used, along with a negative control of the prepared medium without the bacteria added. The concentrations of bacterial cells were determined at the beginning $(t=0 \mathrm{~h})$, and after 8 , 24 , and $48 \mathrm{~h}$ of incubation at $42{ }^{\circ} \mathrm{C}$ under microaerobic conditions, by disturbed sampling, where tubes containing the samples were taken from the microaerobic atmosphere, mixed, sampled, and then returned to the incubations under the appropriate conditions. All of the samples throughout all of the incubations were taken from the same tube. Three biological replicates were carried out, with up to three technical replicates.

\subsection{Growth of B. subtilis PS-216 in Nonsterile Broiler Chicken Intestinal Content Medium}

To determine the suitability of $B$. subtilis PS-216 for use in broiler chickens, its growth was determined in a nonsterile broiler chicken intestinal-content medium. For this purpose, the broiler chicken intestinal content was diluted in phosphate-buffered saline at a ratio of 1:1 (v/v), and homogenized (but not sterilized). The initial B. subtilis PS-216 inoculum was approx. $5 \times 10^{2} \mathrm{CFU} / \mathrm{mL}$, which consisted of $2 \times 10^{2} \mathrm{CFU} / \mathrm{mL}$ vegetative cells and $3 \times 10^{2} \mathrm{CFU} / \mathrm{mL}$ spores. As a background control, the medium was also prepared without added $B$. subtilis. The concentrations of the vegetative bacterial cells and spores were determined at the beginning $(t=0 \mathrm{~h})$, and after 8,24 , and $48 \mathrm{~h}$ of incubation under microaerobic conditions in the inoculated samples and in the control samples without inoculated B. subtilis. Three biological replicates were carried out, with up to three technical 
replicates. The vegetative cell counts were obtained by subtracting the numbers of spores (after heat treatment at $80^{\circ} \mathrm{C}$ for $15 \mathrm{~min}$ ) determined from the total number of colonies from the untreated samples, and the background growth (uninoculated samples) was considered in the calculations.

\subsection{Statistical Analysis}

To evaluate the influence of cocultivation on B. subtilis and C. jejuni growth, MannWhitney U-tests were used. All of the analyses were performed with SPSS software, version 22 (IBM Corp., Armonk, NY, USA) and $p<0.05$ was considered as statistically significant.

\section{Results}

\subsection{B. subtilis PS-216 Reduces C. jejuni Growth}

The interactions of C. jejuni NCTC 11168 and B. subtilis PS-216 were determined during cocultivation.

We first cocultured B. subtilis and C. jejuni in MHB at the B. subtilis:C. jejuni ratios of 10:1 and 1:10. After $4 \mathrm{~h}$ and $8 \mathrm{~h}, B$. subtilis did not show any detectable effects on $C$. jejuni growth, regardless of the B. subtilis:C. jejuni ratio (Figure 1A,B). However, after $24 \mathrm{~h}$ at both the 10:1 and 1:10 ratios, the presence of $B$. subtilis resulted in reduced $C$. jejuni counts (log reduction, 3.87, 4.07, respectively). After $48 \mathrm{~h}$, the $C$. jejuni counts were below the limit of detection for both of these cocultures (Figure 1A,B).
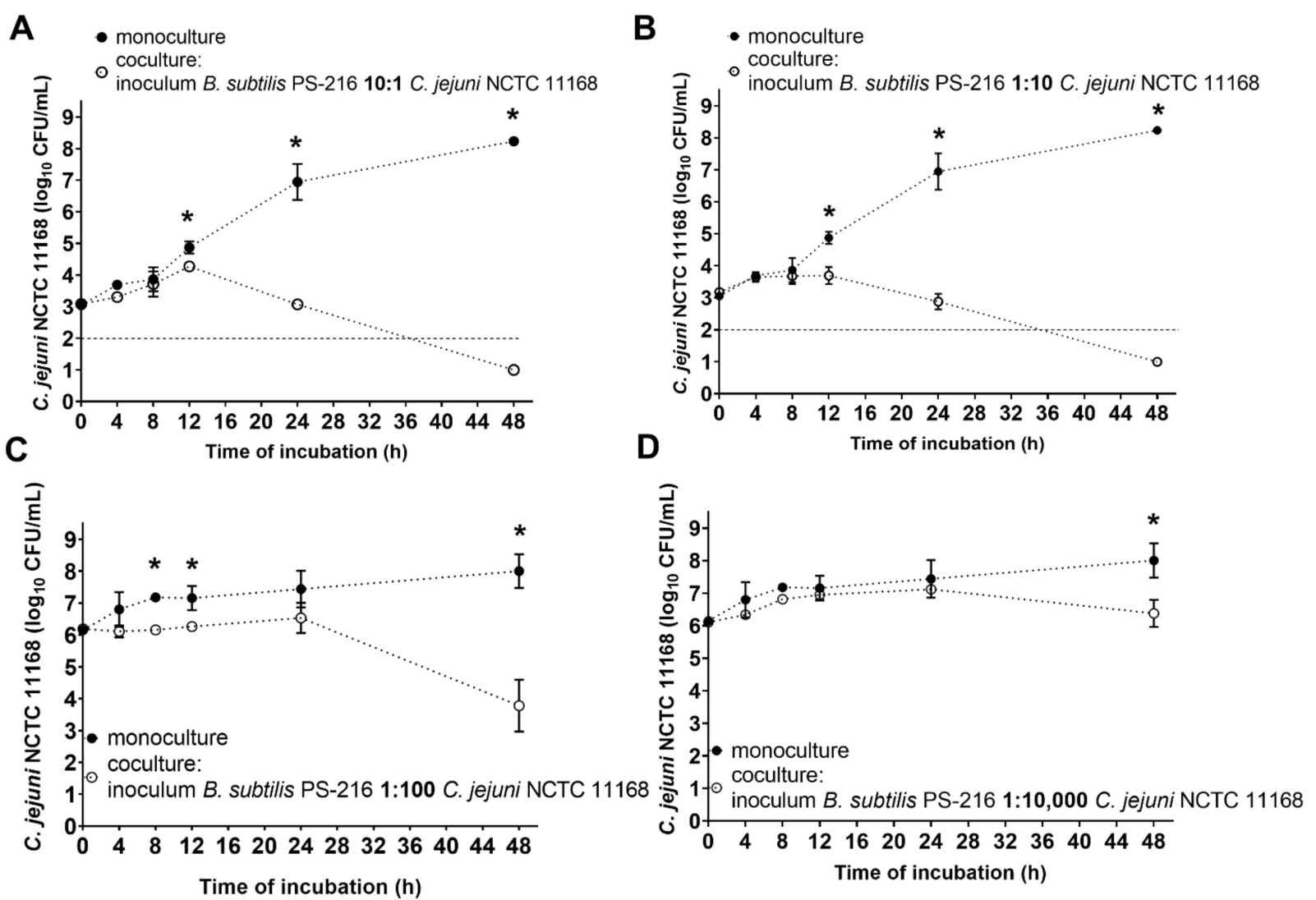

Figure 1. Effects of B. subtilis PS-216 coculture on growth of $C$. jejuni NCTC 11168 compared to $C$. jejuni in monoculture, at the starting B. subtilis:C. jejuni inoculum ratios of 10:1 (A), 1:10 (B), 1:100 (C), and 1:10,000 (D) in Mueller-Hinton broth at $42{ }^{\circ} \mathrm{C}$ under microaerobic conditions over $48 \mathrm{~h}$. Data are means \pm standard deviation of three replicates. Data below the limit of detection (A, B, dotted line) are given as $1 \log _{10} \mathrm{CFU} / \mathrm{mL} .{ }^{*}, p<0.05$ (Mann-Whitney U-tests). 
When B. subtilis was outnumbered by C. jejuni by 100 -fold in the starting inoculum (i.e., B. subtilis:C. jejuni, 1:100), the C. jejuni counts were reduced by 0.91 log units after $24 \mathrm{~h}$, and by $4.22 \mathrm{log}$ units after $48 \mathrm{~h}$ (Figure 1C). The anti-Campylobacter effects of $B$. subtilis were weaker when B. subtilis was initially 10,000-fold lower (B. subtilis:C. jejuni, 1:10,000), as no significant reduction in C. jejuni was seen after $24 \mathrm{~h}$ (Figure 1D, log reduction, 0.32). However, after $48 \mathrm{~h}$, the $C$. jejuni counts here were significantly decreased by $1.62 \log$ units. This shows that B. subtilis is strongly competitive, as the growth inhibition of $C$. jejuni was seen even when $B$. subtilis was greatly outnumbered by $C$. jejuni. On the other hand, the growth of $B$. subtilis was not affected by the presence of $C$. jejuni, regardless of the initial inoculum ratios (Figure $\mathrm{S} 1$ ).

\subsection{B. subtilis PS-216 Anti-Campylobacter Effects Increase at Higher Temperatures}

We investigated the interactions of B. subtilis PS-216 and C. jejuni NCTC 11168 in MHB at the starting ratio of 1:10 (B. subtilis:C. jejuni) and under microaerobic conditions, at $42{ }^{\circ} \mathrm{C}$ (to mimic the chicken gut), $37^{\circ} \mathrm{C}$ (to mimic the human gut), and $20{ }^{\circ} \mathrm{C}$ (as the room/environment temperature). Here, the presence of $B$. subtilis PS-216 significantly reduced C. jejuni growth at $42{ }^{\circ} \mathrm{C}$ and $37^{\circ} \mathrm{C}$, while no impact on C. jejuni NCTC 11168 survival was noted at $20{ }^{\circ} \mathrm{C}$ (Figure $2 \mathrm{~A}-\mathrm{C}$ ). After $24 \mathrm{~h}$ at $42{ }^{\circ} \mathrm{C}$, the C. jejuni counts in the co-cultures were reduced by $4.19 \log$ units $(p<0.05)$, compared to the monoculture, and after $48 \mathrm{~h}$ by $>6.5 \log$ units (Figure $2 \mathrm{~A}$ ). At $37^{\circ} \mathrm{C}$, the $\mathrm{C}$. jejuni counts after $24 \mathrm{~h}$ and $48 \mathrm{~h}$ were reduced by $1.63 \log$ units and $2.68 \log$ units, respectively ( $p<0.05$, for both), as compared to the control monoculture (Figure 2B). The effects of B. subtilis were weaker at $37{ }^{\circ} \mathrm{C}$ compared to $42^{\circ} \mathrm{C}$ under these microaerobic conditions, but remained significant. In contrast, at $20^{\circ} \mathrm{C}$, B. subtilis PS-216 did not show any significant anti-Campylobacter effects (Figure 2C). These data show that the environmental temperature has a crucial role in the interactions between B. subtilis and C. jejuni. For the B. subtilis PS-216 counts after $48 \mathrm{~h}$, although they were a little higher in the monoculture, they again showed no significant differences between the mono- and cocultures. They were, however, significantly higher at $42{ }^{\circ} \mathrm{C}$ and $37^{\circ} \mathrm{C}$, compared to $20^{\circ} \mathrm{C}$ (Figure 2D).

\subsection{Protective Effects of B. subtilis PS-216 for C. jejuni under Aerobic Conditions}

Here, we tested the effects of B. subtilis PS-216 on the survival of C. jejuni NCTC 11168 at the starting ratio of $1: 10$ (B. subtilis:C. jejuni) at $37{ }^{\circ} \mathrm{C}$ and $20^{\circ} \mathrm{C}$ under aerobic growth conditions, representing conditions found on the surface and surroundings of broiler chickens. Protective, rather than inhibitory, effects of B. subtilis PS-216 on C. jejuni were seen in these cocultures at both $37^{\circ} \mathrm{C}$ and $20^{\circ} \mathrm{C}$ (Figure 3). Under these aerobic conditions, $C$. jejuni did not undergo growth in the mono- or cocultures; indeed, after $48 \mathrm{~h}$ in the monoculture at $37^{\circ} \mathrm{C}$, no C. jejuni was detected, whereas the C. jejuni counts in the coculture remained comparable to the starting inoculum (Figure 3A). Again, no significant differences were seen for $B$. subtilis PS-216 growth in the cocultures, compared to monocultures (Figure 3).

\subsection{Anti-Campylobacter Effects of B. subtilis PS-216 Are More Prominent in Chicken Litter Than in Intestinal Content}

To evaluate the anti-Campylobacter effects of B. subtilis PS-216 in an environment closer to the conditions where these two bacteria might interact, a sterile chicken litter medium and a chicken intestinal-content medium were prepared. Chicken litter is a complex mixture of excreted chicken fecal matter and cellulose material. In the chicken litter medium, C. jejuni growth was strongly inhibited by B. subtilis (Figure 4A). After $8 \mathrm{~h}$ of this incubation with B. subtilis, the C. jejuni counts were significantly reduced by 1.18 log units, and after $24 \mathrm{~h}$, no C. jejuni was detected in the chicken litter medium. This anti-Campylobacter effect of B. subtilis PS-216 was stronger in the chicken litter medium compared to the effects in MHB: in the $B$. subtilis PS-216 cocultures (starting ratio, 1:10) after $24 \mathrm{~h}$, the log reductions in C. jejuni counts in MHB (Figure 1B) and in the sterilized chicken litter medium (Figure 4A) 
were 4.07 and $>6$, respectively. The $B$. subtilis growth in the sterilized chicken litter medium was not affected by the presence of C. jejuni (Figure S2A), and was comparable with MHB.

A

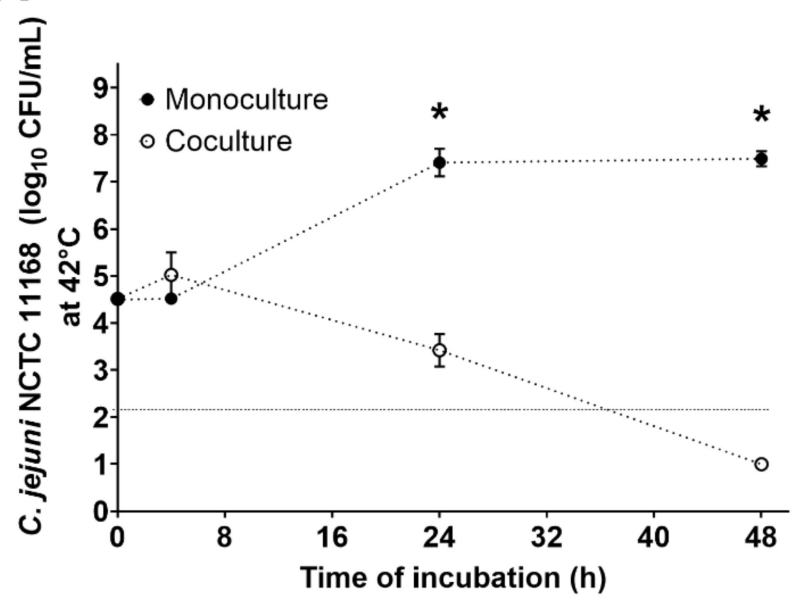

C

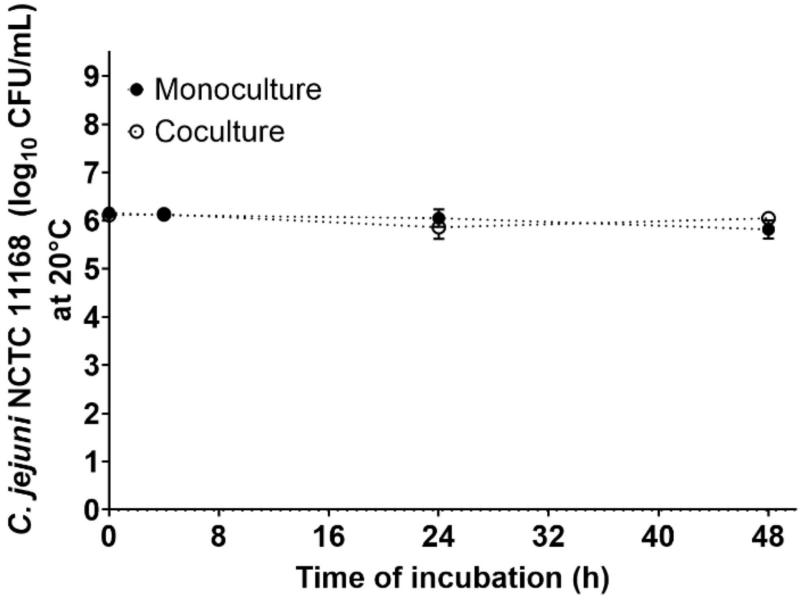

B

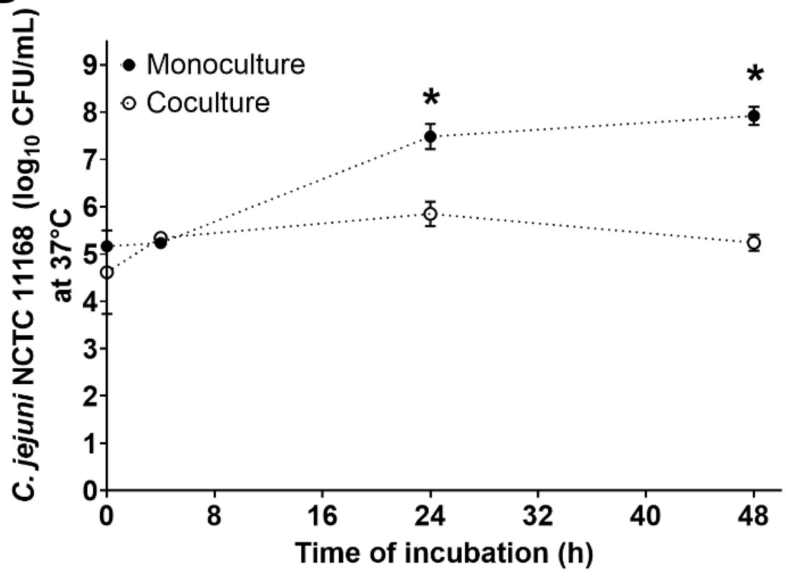

D

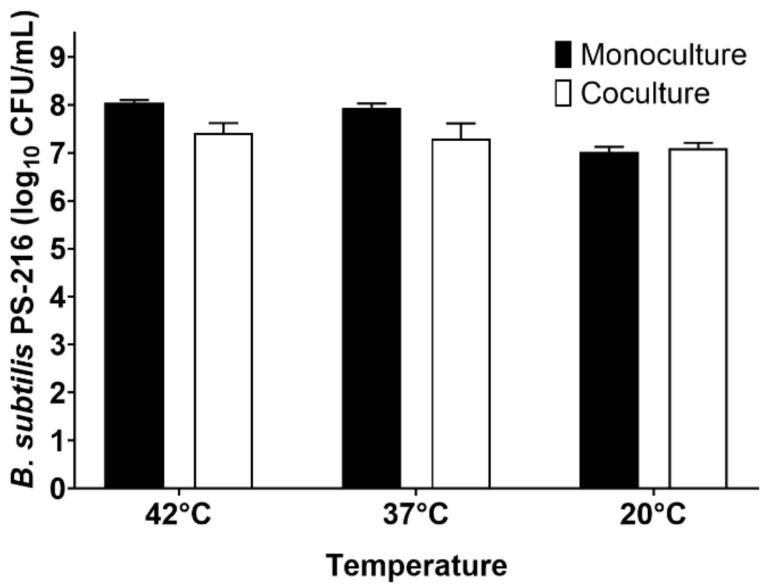

Figure 2. (A-C) Effects of B. subtilis PS-216 coculture on growth of C. jejuni NCTC 11168 compared to C. jejuni in monoculture, at the starting B. subtilis: C. jejuni inoculum ratio of 1:10 in Mueller-Hinton broth at $42{ }^{\circ} \mathrm{C}(\mathbf{A}), 37^{\circ} \mathrm{C}(\mathbf{B})$, and $20^{\circ} \mathrm{C}(\mathbf{C})$ under microaerobic conditions over $48 \mathrm{~h}$. Data below the limit of detection (A, dotted line) are given as $1 \log _{10} \mathrm{CFU} / \mathrm{mL}$. (D) B. subtilis PS-216 counts under the same conditions as for $(\mathbf{A}-\mathbf{C})$. Data are means \pm standard deviation of three replicates. ${ }^{*}, p<0.05$ (Mann-Whitney U-tests).

In the chicken intestinal-content medium, the B. subtilis cocultures did not show any bactericidal effects against $C$. jejuni, as $C$. jejuni continued to grow for $48 \mathrm{~h}$ even in the presence of $B$. subtilis (Figure $4 \mathrm{~B}$ ), although at a significantly slower rate than in the monoculture. Here, B. subtilis reduced the C. jejuni counts by $2.26 \log$ units at $24 \mathrm{~h}$, and $1.84 \log$ units at $48 \mathrm{~h}$ of coculture. The less dramatic effect of $B$. subtilis here can be explained by its hindered growth in the sterile intestinal-content medium (Figure S2B).

\subsection{B. subtilis PS-216 Growth and Sporulation Are Limited in Nonsterile Chicken Intestinal Content Medium}

We cultivated B. subtilis PS-216 in the nonsterile chicken intestinal-content medium to follow its growth and sporulation for $48 \mathrm{~h}$ at $42{ }^{\circ} \mathrm{C}$ under microaerobic conditions. After an initial drop in the vegetative cell counts due to sporulation, the B. subtilis grew to the final count of $4.54 \log _{10} \mathrm{CFU} / \mathrm{mL}$ after $48 \mathrm{~h}$ of incubation (Figure 5). These cells did not sporulate, as after $24 \mathrm{~h}$ the spore counts were below, and remained below, the limit of detection. 
A

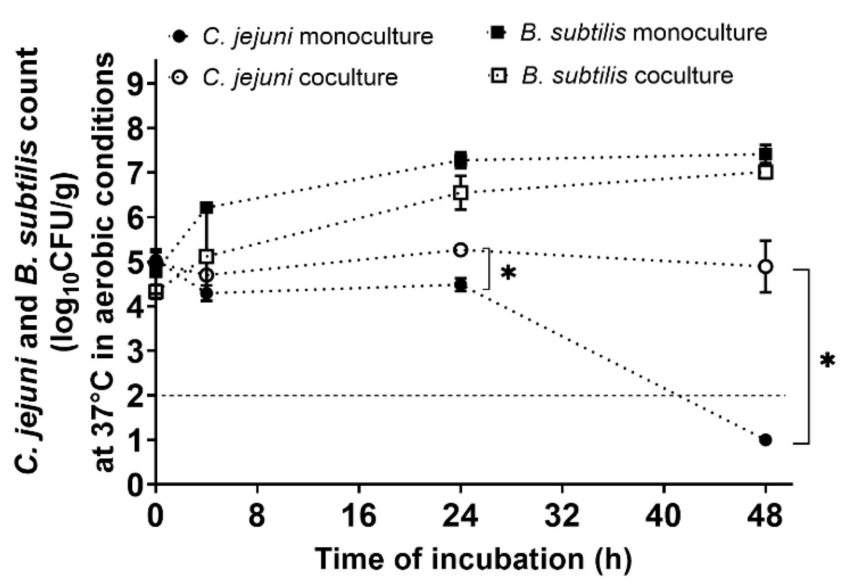

B

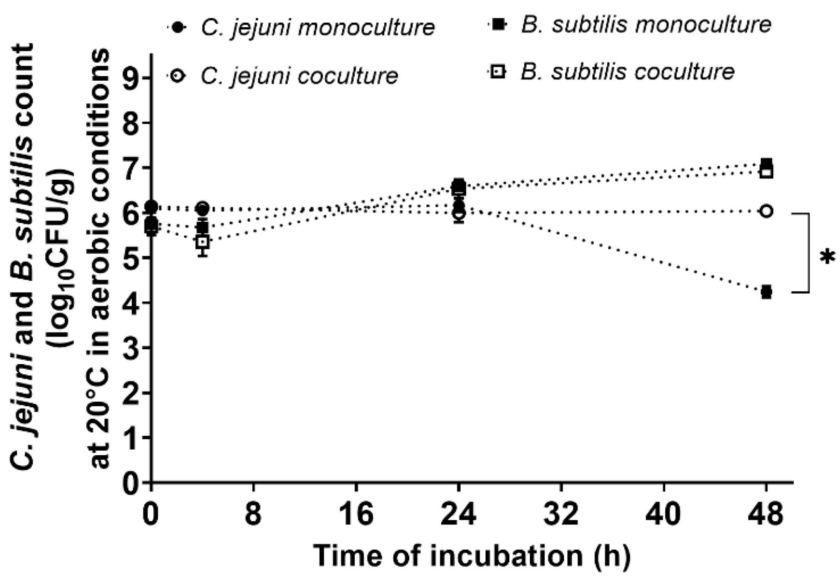

Figure 3. Effects of coculturing on growth of B. subtilis PS-216 and C. jejuni NCTC 11168 at the starting B. subtilis:C. jejuni inoculum ratio of $1: 10$ in Mueller-Hinton broth at $37^{\circ} \mathrm{C}(\mathbf{A})$ and $20^{\circ} \mathrm{C}(\mathbf{B})$ under aerobic conditions over $48 \mathrm{~h}$. Data are means \pm standard deviation of three replicates. Data below the limit of detection (A, dotted line) are given as $1 \log _{10} \mathrm{CFU} / \mathrm{mL} .{ }^{*}, p<0.05$ (Mann-Whitney U-tests).
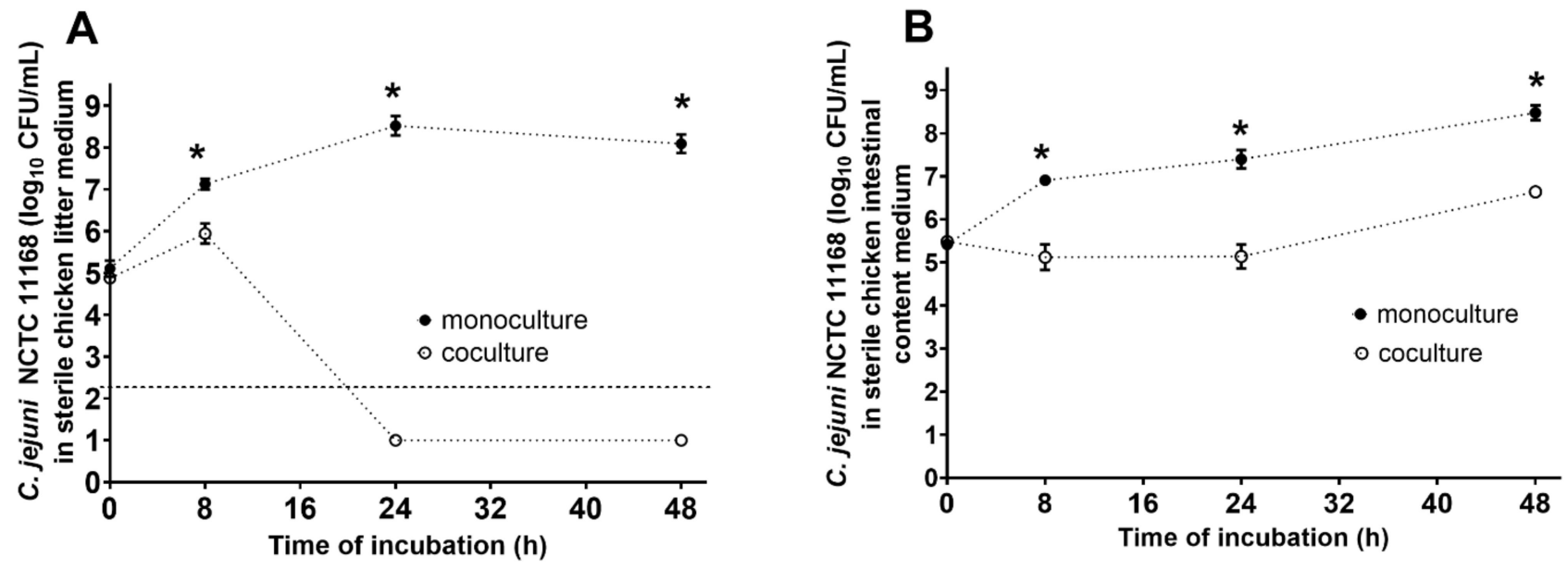

Figure 4. Effects of B. subtilis PS-216 coculture on growth of C. jejuni NCTC 11168 compared to C. jejuni in monoculture at the starting B. subtilis: C. jejuni inoculum ratio of 1:10 in sterile chicken litter medium (A) and sterile chicken intestinal-content medium (B) over $48 \mathrm{~h}$. Data are means \pm standard deviation of three replicates. Data below the limit of detection (A, dotted line) are given as $1 \log _{10} \mathrm{CFU} / \mathrm{mL} .{ }^{*}, p<0.05$ (Mann-Whitney U-tests).

The interaction of C. jejuni and B. subtilis was not examined under these conditions, as C. jejuni did not survive in the nonsterile intestinal content in the monoculture inoculated at $10^{4} \mathrm{CFU} / \mathrm{mL}$ and $10^{6} \mathrm{CFU} / \mathrm{mL}$ (data not shown). 


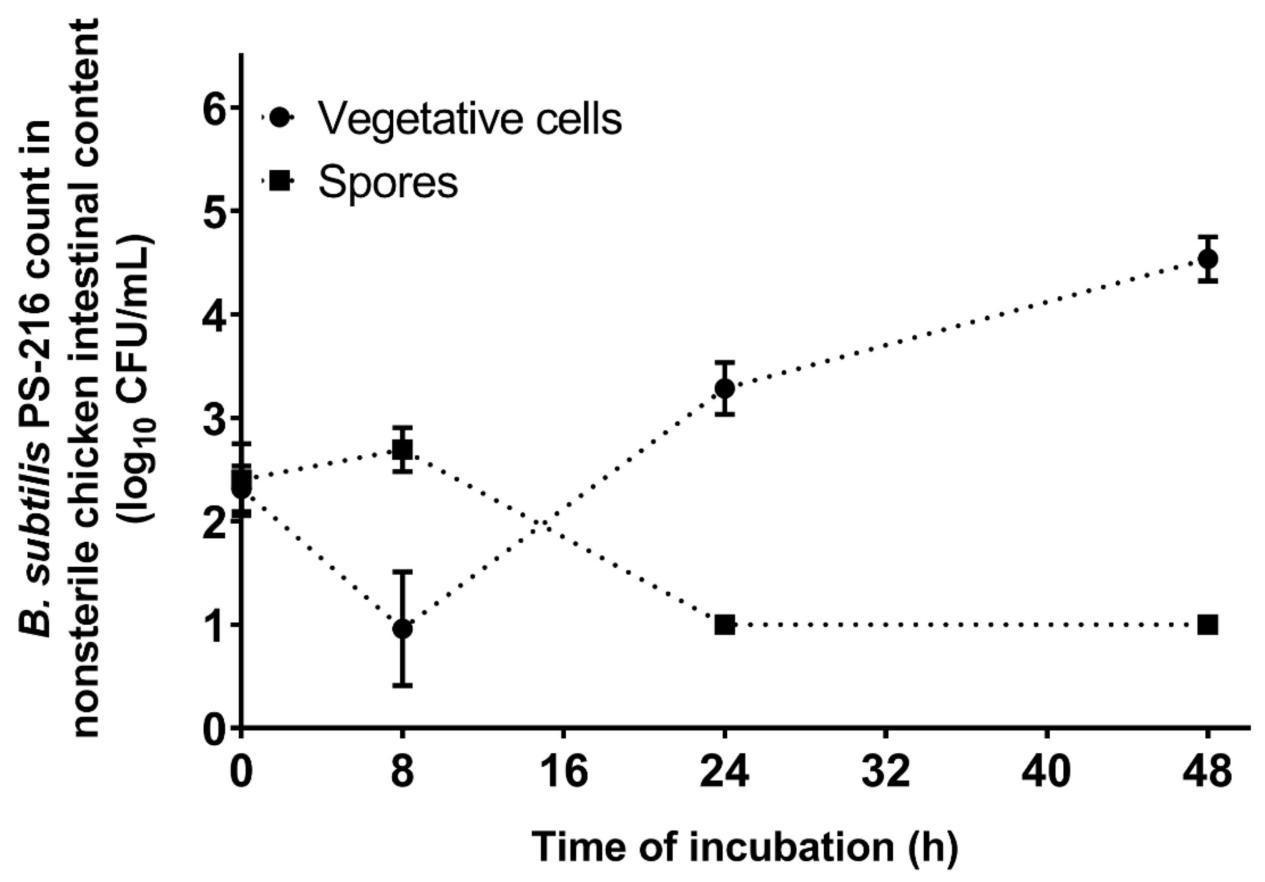

Figure 5. B. subtilis PS-216 growth (vegetative cells) and sporulation (spores) in nonsterile chicken intestinal-content medium at $42{ }^{\circ} \mathrm{C}$ under microaerobic conditions over $48 \mathrm{~h}$. Data are means \pm standard deviation of three replicates.

\section{Discussion}

The persistence of $C$. jejuni in poultry production represents a considerable food safety hazard, and is, thus, an urgent problem that needs to be resolved. Although safety measures are being implemented, the need for additional interventions persists. One potential intervention is the addition of probiotic bacteria that can substantially reduce the C. jejuni load in the chicken host $[1,5,6]$. B. subtilis is a spore-forming bacterium that is often found in the chicken gut and is being investigated for probiotic use, with varying results. However, little is known about how environmental parameters influence the interactions between B. subtilis and C. jejuni.

Thus, we here characterized the interactions between B. subtilis-PS-216 and C. jejuni NCTC 11168 in laboratory media in terms of temperature and the atmosphere of the cultivation, and also in the more complex environments of a chicken litter medium and a chicken intestinal-content medium. All of the tested parameters influenced the active growth and survival of $C$. jejuni when in coculture with B. subtilis.

Specifically, at $42{ }^{\circ} \mathrm{C}$ and under the microaerobic conditions that favor $C$. jejuni growth, B. subtilis PS-216 inhibited C. jejuni growth even when B. subtilis was initially strongly outnumbered by $C$. jejuni. This could be important in the chicken gut, where $C$. jejuni can be found in high numbers of up to $10^{9} \mathrm{CFU} / \mathrm{g}$ feces $[34,35]$, although additional in vivo experiments must be performed to confirm this. This growth inhibition of $C$. jejuni by B. subtilis PS-216 is consistent with our previous findings [21]. Here, this was extended to interaction studies also at $37^{\circ} \mathrm{C}$ and $20^{\circ} \mathrm{C}$; this $B$. subtilis PS-216 growth inhibitory effect on C. jejuni at $42{ }^{\circ} \mathrm{C}$ was reduced already at $37^{\circ} \mathrm{C}$, and then lost at $20^{\circ} \mathrm{C}$ (Figure 2). Indeed, no active growth of $C$. jejuni is expected at temperatures $<32{ }^{\circ} \mathrm{C}$, although the metabolic activity of $C$. jejuni has been reported at temperatures as low as $4{ }^{\circ} \mathrm{C}$ [28]. Our results thus indicate that for strong anti-Campylobacter effects of B. subtilis seen as a reduction of $C$. jejuni numbers as compared to the control monoculture, active growth of $C$. jejuni is required. The incubation temperature can also affect the $B$. subtilis antimicrobial synthesis and antagonistic behavior towards other species [31,32], which might also apply to these cocultivations with $C$. jejuni. Moreover, higher growth inhibition of B. subtilis PS-216 at higher temperatures suggests that this $B$. subtilis strain might have greater benefits 
in the chicken host (i.e., at $42{ }^{\circ} \mathrm{C}$ ) than in a human host (i.e., at $37{ }^{\circ} \mathrm{C}$ ). However, the gastrointestinal tract of animals is a complex environment and the in vitro inhibition data might not translate to in vivo settings.

Campylobacter jejuni growth is strongly limited by the presence of oxygen. C. jejuni requires an oxygen tension of $2 \%$ to $10 \%$ for growth, and it is also sensitive to higher oxygen concentrations [22]; in contrast, B. subtilis can thrive under these conditions. Here, we showed that the interactions between B. subtilis and C. jejuni also changed drastically under aerobic conditions, as B. subtilis supported the survival of $C$. jejuni at $37{ }^{\circ} \mathrm{C}$ and $20^{\circ} \mathrm{C}$ (Figure 3). Similar phenomena were described by Ica et al. [36] and Hilbert et al. [24], where they reported that other species (i.e., Pseudomonas spp., Staphylococcus spp.) can protect $C$. jejuni from harmful atmospheric conditions. Indeed, a good example of this was provided by Culotti and Packman [23], where C. jejuni grew in biofilms under aerobic conditions in cocultures with Pseudomonas aeruginosa. Here, it was indicated that the active growth and respiration of Pseudomonas spp. can lower the oxygen concentration of the local environment, and thus provide protection for C. jejuni [23]. As anti-Campylobacter effects will only be apparent when $C$. jejuni is actively growing, the protective effects seen here for B. subtilis under aerobic conditions are not surprising. Under these conditions, where oxygen levels would be toxic to $C$. jejuni, there would be no obvious antagonistic effects, although $B$. subtilis would still reduce oxygen in the environment. Therefore, this could be a food safety concern, as it could promote the survival and persistence of $C$. jejuni in the environment.

The reduction of C. jejuni in broiler chickens using a probiotic such as B. subtilis might represent a promising tool in the control of $C$. jejuni. Fritts et al. [37] reported that B. subtilis C-3120 (known as Calsporin) can slightly reduce C. jejuni on broiler carcasses (log reduction, 0.2), and later, Guyard-Nicodeme et al. [38] confirmed the reduction of C. jejuni in the cecum content (1.7 log reduction). This anti-Campylobacter effect was not seen for B. subtilis DSM17299 [39]. This suggests that B. subtilis has strain-specific anti-Campylobacter activity, and thus, there is the need to better characterize the interactions of these two organisms to evaluate their potential as new probiotics for $C$. jejuni control.

As cocultivation of $B$. subtilis and $C$. jejuni at $42{ }^{\circ} \mathrm{C}$ under microaerobic conditions resulted in reductions in $C$. jejuni growth, we also used simple model systems of chicken litter and chicken intestinal content to evaluate the potential B. subtilis anti-Campylobacter activity in poultry. These two media had different compositions. The litter was a mixture of chicken excreta and cellulose material from used bedding, whereas the intestinal content contained less undigested cellulose material. In the medium containing sterile chicken litter, B. subtilis growth was comparable to its growth in the rich laboratory medium of MHB (Figure S2A), while its anti-Campylobacter effects were much stronger. This excellent growth of B. subtilis PS-216 in the sterile chicken litter medium might also be due to the heat treatment of cellulose material from the bedding and possible subsequent release of sugars [40]. The intestinal content is expected to have less cellulose material, and thus, fewer nutrients compared to the chicken litter medium after autoclaving. In the chicken intestinal-content medium, the B. subtilis anti-Campylobacter effects were not clearly bactericidal, although significant reduction of $C$. jejuni growth was still obtained, compared to the untreated control (Figure 4). The reduced effects of B. subtilis here would not be affected by hindered $C$. jejuni growth, as it was comparable to the growth in laboratory media, but could rather be explained by the hindered growth of $B$. subtilis in the sterile chicken intestinal-content medium (Figure S2B), and thus resulting in a reduced killing effect. As the compositions of chicken bedding (and, thus, litter) and also the intestinal content of different animals can be variable, this interaction of B. subtilis and C. jejuni in the media from chicken litter and intestinal content seen in this study might be expected to vary accordingly.

Bacillus subtilis strains have been shown to have enzymes for the breakdown of complex materials such as cellulose, xylan, and levan, and to grow in highly competitive environments such as chicken feces [41-45]. The hydrolysis of indigestible complex carbo- 
hydrates to simple sugars by bacteria in the chicken gut allows for their further fermentation and use by the host as energy and carbon sources. This can further feed conversion and growth of broiler chickens [45], making research into B. subtilis as a probiotic interesting from the perspectives of animal health and growth enhancement, as well as antipathogenic effects.

The finding that active growth of $C$. jejuni might be required for the inhibitory effects of B. subtilis makes B. subtilis suitable for C. jejuni control in the gut, where C. jejuni will replicate. Conversely, $B$. subtilis does not appear to be suitable as a $C$. jejuni antagonist for environments rich in oxygen or at lower temperatures, as are often found on exposed surfaces such as the ground, water feeders, or feathers. Indeed, this might represent a challenge, as B. subtilis might even promote the survival of $C$. jejuni in aerobic environments, and thus contribute to the persistence of $C$. jejuni in the environment instead, although more studies are necessary to confirm this.

For a $B$. subtilis strain to be effective against $C$. jejuni in an environment with a naturally occurring high microbiological burden such as the chicken gut, it has to be resistant to the negative effects of this environment, and thus, be competitive and grow here. B. subtilis PS-216 actively grew in the nonsterile chicken intestinal-content medium, where it had to compete with the normal chicken intestine microbiota under oxygen-limiting conditions. Interestingly, the B. subtilis spores germinated in the chicken intestinal-content medium, although no sporulation occurred, even after $48 \mathrm{~h}$ of incubation (Figure 5). Cartman et al. (2008) [46] have also shown that B. subtilis spores can germinate in the chicken gut. They showed that at $20 \mathrm{~h}$ postexposure with $B$. subtilis spores, the numbers of vegetative cells were higher compared to the spore counts. These in vivo findings are consistent with the present in vitro results, and strongly suggest that B. subtilis spores will germinate in the chicken gut, and that cell replication will occur.

The good anti-Campylobacter activity shown here under conditions close to the chicken gut allow us to propose B. subtilis PS-216 as a promising candidate for C. jejuni control, and potentially as an interesting probiotic for use in poultry production.

\section{Conclusions}

Bacillus subtilis PS-216 has shown strong anti-Campylobacter effects, whereby the growth temperature and medium, and the presence of oxygen have vital roles in the B. subtilis and C. jejuni interactions and growth dynamics. In an environment with actively growing B. subtilis and C. jejuni, such as the chicken gut, we can expect B. subtilis to reduce C. jejuni growth. However, further in vitro experiments, including a variety of $C$. jejuni strains also resistant to antimicrobials (as would be found on poultry farms), and in vivo experiments including poultry animals are needed to confirm this hypothesis. In contrast, B. subtilis might not be suitable for $C$. jejuni control in environments that are unfavorable for C. jejuni, as it fails to antagonize the nongrowing pathogen, and might even provide protection for C. jejuni.

\section{Patents}

Mandic Mulec I, Simunovic K, Stefanic P, Erega A, Smole Možina S, Klančnik A, Zhang Q, Sahin O. 23 November 2020, filing date. Bacillus subtilis strain with strong inhibition of enteropathogenic and foodborne pathogenic bacteria. US patent application 63117215. EFS ID: 41197988, confirmation number: 4289.

Supplementary Materials: The following are available online at https: / www.mdpi.com/article/ 10.3390/microorganisms10020289/s1, Figure S1: Growth of B. subtilis PS-216 in monoculture and in coculture with $C$. jejuni NCTC 11168, at 10:1 in favor of B. subtilis, and 1:10, 1:100, and 1:10,000 in favor of $C$. jejuni in the starting inoculum in $\mathrm{MHB}$ at $42{ }^{\circ} \mathrm{C}$ under microaerobic conditions, presented as $\log _{10} \mathrm{CFU} / \mathrm{mL} \pm$ standard deviation of three replicates, Figure S2. Growth of B. subtilis PS216 in sterile chicken litter medium (A) and sterile intestinal-content medium (B), in monoculture (filled symbols) and coculture (empty symbols), presented as $\log _{10} \mathrm{CFU} / \mathrm{mL} \pm$ standard deviation of three replicates. 
Author Contributions: Conceptualization, K.Š., P.S., A.K., I.M.M. and S.S.M.; methodology, K.Š., P.S. and A.K.; validation, K.Š., P.S. and A.K.; formal analysis, K.Š.; investigation, K.Š.; resources, I.M.M. and S.S.M.; data curation, K.Š.; writing—original draft preparation, K.Š.; writing-review and editing, P.S., A.K., A.E., I.M.M. and S.S.M.; visualization, K.Š.; supervision, P.S., A.K., I.M.M. and S.S.M.; project administration, I.M.M. and S.S.M.; funding acquisition, I.M.M. and S.S.M. All authors have read and agreed to the published version of the manuscript.

Funding: This research was funded by the Slovenian Research Agency (ARRS), projects J4-7637 and J4-2542, and program P4-0116.

Institutional Review Board Statement: Not applicable.

Informed Consent Statement: Not applicable.

Data Availability Statement: Data supporting the reported results can be retrieved from the authors.

Acknowledgments: The authors would like to thank Bojan Pahor of Perutnina Ptuj d.d. for providing the broiler chicken litter, and Angela Borovnica s.p. for providing the broiler chicken intestinal content. The authors also thank Katarina Krapež for technical support.

Conflicts of Interest: The authors declare that they have no conflict of interest.

\section{References}

1. EFSA. ECDC The European Union One Health 2019 Zoonoses Report. EFSA J. 2021, 19, e06406. [CrossRef]

2. Kaakoush, N.O.; Castaño-Rodríguez, N.; Mitchell, H.M.; Man, S.M. Global Epidemiology of Campylobacter Infection. Clin. Microbiol. Rev. 2015, 28, 687-720. [CrossRef] [PubMed]

3. EFSA and ECDC European Food Safety Authority and European Centre for Disease Prevention and Control. The European Union Summary Report on Trends and Sources of Zoonoses, Zoonotic Agents and Food-Borne Outbreaks in 2017. EFSA J. 2018, 16, e05500. [CrossRef]

4. Ellyn, P.; Marder, M.P.H.; Griffin, P.M.; Cieslak, P.R.; Dunn, J.; Hurd, S.; Jervis, R.; Lathrop, S.; Muse, A.; Ryan, P.; et al. Preliminary Incidence and Trends of Infections with Pathogens Transmitted Commonly Through Food-Foodborne Diseases Active Surveillance Network, 10 U.S. Sites, 2006-2017. MMWR Morb. Mortal. Wkly. Rep. 2018, 67, 324-328. [CrossRef]

5. Koutsoumanis, K.; Allende, A.; Alvarez-Ordóñez, A.; Bolton, D.; Bover-Cid, S.; Davies, R.; Cesare, A.D.; Herman, L.; Hilbert, F.; Lindqvist, R.; et al. Update and Review of Control Options for Campylobacter in Broilers at Primary Production. EFSA J. 2020, 18, e06090. [CrossRef]

6. Meunier, M.; Guyard-Nicodème, M.; Dory, D.; Chemaly, M. Control Strategies against Campylobacter at the Poultry Production Level: Biosecurity Measures, Feed Additives and Vaccination. J. Appl. Microbiol. 2016, 120, 1139-1173. [CrossRef]

7. Dogan, O.B.; Clark, J.; Mattos, F.; Wang, B. A Quantitative Microbial Risk Assessment Model of Campylobacter in Broiler Chickens: Evaluating Processing Interventions. Food Control 2019, 100, 97-110. [CrossRef]

8. Foster, K.R.; Bell, T. Competition, Not Cooperation, Dominates Interactions among Culturable Microbial Species. Curr. Biol. 2012, 22, 1845-1850. [CrossRef]

9. Thomrongsuwannakij, T.; Chuanchuen, R.; Chansiripornchai, N. Identification of Competitive Exclusion and Its Ability to Protect against Campylobacter jejuni in Broilers. Thai J. Vet. Med. 2016, 46, 279-286.

10. Schouls, L.M.; Reulen, S.; Duim, B.; Wagenaar, J.A.; Willems, R.J.L.; Dingle, K.E.; Colles, F.M.; Van Embden, J.D.A. Comparative Genotyping of Campylobacter jejuni by Amplified Fragment Length Polymorphism, Multilocus Sequence Typing, and Short Repeat Sequencing: Strain Diversity, Host Range, and Recombination. J. Clin. Microbiol. 2003, 41, 15-26. [CrossRef]

11. Stern, N.J. Mucosal Competitive Exclusion to Diminish Colonization of Chickens by Campylobacter jejuni. Poult. Sci. 1994, 73, 402-407. [CrossRef] [PubMed]

12. Zhang, G.; Ma, L.; Doyle, M.P. Potential Competitive Exclusion Bacteria from Poultry Inhibitory to Campylobacter jejuni and Salmonella. J. Food Prot. 2007, 70, 867-873. [CrossRef] [PubMed]

13. Saint-Cyr, M.J.; Guyard-Nicodème, M.; Messaoudi, S.; Chemaly, M.; Cappelier, J.-M.; Dousset, X.; Haddad, N. Recent Advances in Screening of Anti-Campylobacter Activity in Probiotics for Use in Poultry. Front. Microbiol. 2016, 7, 553. [CrossRef] [PubMed]

14. Mañes-Lázaro, R.; Van Diemen, P.M.; Pin, C.; Mayer, M.J.; Stevens, M.P.; Narbad, A. Administration of Lactobacillus Johnsonii FI9785 to Chickens Affects Colonisation by Campylobacter jejuni and the Intestinal Microbiota. Br. Poult. Sci. 2017, 58, 373-381. [CrossRef]

15. Ma, Y.; Wang, W.; Zhang, H.; Wang, J.; Zhang, W.; Gao, J.; Wu, S.; Qi, G. Supplemental Bacillus subtilis DSM 32315 Manipulates Intestinal Structure and Microbial Composition in Broiler Chickens. Sci. Rep. 2018, 8, 15358. [CrossRef]

16. Neijat, M.; Shirley, R.B.; Welsher, A.; Barton, J.; Thiery, P.; Kiarie, E. Growth Performance, Apparent Retention of Components, and Excreta Dry Matter Content in Shaver White Pullets (5 to 16 Week of Age) in Response to Dietary Supplementation of Graded Levels of a Single Strain Bacillus subtilis Probiotic. Poult. Sci. 2019, 98, 3777-3786. [CrossRef] 
17. Tamehiro, N.; Okamoto-Hosoya, Y.; Okamoto, S.; Ubukata, M.; Hamada, M.; Naganawa, H.; Ochi, K. Bacilysocin, a Novel Phospholipid Antibiotic Produced by Bacillus subtilis 168. Antimicrob. Agents Chemother. 2002, 46, 315-320. [CrossRef]

18. Sharma, G.; Dang, S.; Gupta, S.; Gabrani, R. Antibacterial Activity, Cytotoxicity, and the Mechanism of Action of Bacteriocin from Bacillus subtilis GAS101. Med. Princ. Pract. 2018, 27, 186-192. [CrossRef]

19. Caulier, S.; Nannan, C.; Gillis, A.; Licciardi, F.; Bragard, C.; Mahillon, J. Overview of the Antimicrobial Compounds Produced by Members of the Bacillus subtilis Group. Front. Microbiol. 2019, 10, 302. [CrossRef]

20. Khare, A.; Tavazoie, S. Multifactorial Competition and Resistance in a Two-Species Bacterial System. PLoS Genet. 2015, 11, e1005715. [CrossRef]

21. Erega, A.; Stefanic, P.; Dogsa, I.; Danevčič, T.; Simunovic, K.; Klančnik, A.; Možina, S.S.; Mulec, I.M. Bacillaene Mediates the Inhibitory Effect of Bacillus subtilis on Campylobacter jejuni Biofilms. Appl. Environ. Microbiol. 2021, 87, e0295520. [CrossRef] [PubMed]

22. Kaakoush, N.O.; Miller, W.G.; De Reuse, H.; Mendz, G.L. Oxygen Requirement and Tolerance of Campylobacter jejuni. Res. Microbiol. 2007, 158, 644-650. [CrossRef] [PubMed]

23. Culotti, A.; Packman, A.I. Pseudomonas Aeruginosa Facilitates Campylobacter jejuni Growth in Biofilms under Oxic Flow Conditions. FEMS Microbiol. Ecol. 2015, 91, fiv136. [CrossRef] [PubMed]

24. Hilbert, F.; Scherwitzel, M.; Paulsen, P.; Szostak, M.P. Survival of Campylobacter jejuni under Conditions of Atmospheric Oxygen Tension with the Support of Pseudomonas Spp. Appl. Environ. Microbiol. 2010, 76, 5911-5917. [CrossRef]

25. Rasschaert, G.; De Zutter, L.; Herman, L.; Heyndrickx, M. Campylobacter Contamination of Broilers: The Role of Transport and Slaughterhouse. Int. J. Food Microbiol. 2020, 322, 108564. [CrossRef]

26. Nakano, M.M.; Zuber, P. Anaerobic Growth of a "Strict Aerobe" (Bacillus subtilis). Annu. Rev. Microbiol. 1998, 52, 165-190. [CrossRef]

27. Nakano, M.M.; Hulett, F.M. Adaptation of Bacillus subtilis to Oxygen Limitation. FEMS Microbiol. Lett. 1997, 157, 1-7. [CrossRef]

28. Hazeleger, W.C.; Wouters, J.A.; Rombouts, F.M.; Abee, T. Physiological Activity of Campylobacter jejuni Far below the Minimal Growth Temperature. Appl. Environ. Microbiol. 1998, 64, 3917-3922. [CrossRef]

29. Satapute, P.; Olekar, H.S.; Shetti, A.; Kulkarni, A.; Hiremath, G.; Patagundi, B.I.; Shivsharan, C.T.; Kaliwal, B.B. Isolation and Characterization of Nitrogen Fixing Bacillus subtilis Strain As-4 from Agricultural Soil. Int. J. Recent Sci. Res. $2012,3,762-765$.

30. Isnawati; Trimulyono, G. Temperature Range and Degree of Acidity Growth of Isolate of Indigenous Bacteria on Fermented Feed “Fermege". J. Phys. Conf. Ser. 2018, 953, 012209. [CrossRef]

31. Perez, C.; Suarez, C.; Castro, G.R. Production of Antimicrobials by Bacillus subtilis MIR 15. J. Biotechnol. 1992, 26, 331-336. [CrossRef]

32. Jiménez-Delgadillo, R.; Valdés-Rodríguez, S.E.; Olalde-Portugal, V.; Abraham-Juárez, R.; García-Hernández, J.L.; JiménezDelgadillo, R.; Valdés-Rodríguez, S.E.; Olalde-Portugal, V.; Abraham-Juárez, R.; García-Hernández, J.L. Effect of PH and Temperature on the Growth and Antagonistic Activity of Bacillus subtilis on Rhizoctonia Solani. Rev. Mex. Fitopatol. 2018, 36, 256-275. [CrossRef]

33. Štefanič, P.; Mandič-Mulec, I. Social Interactions and Distribution of Bacillus subtilis Pherotypes at Microscale. J. Bacteriol. 2009, 191, 1756-1764. [CrossRef] [PubMed]

34. Stern, N.J.; Robach, M.C. Enumeration of Campylobacter spp. in Broiler Feces and in Corresponding Processed Carcasses. J. Food Prot. 2003, 66, 1557-1563. [CrossRef]

35. Figueroa, G.; Troncoso, M.; López, C.; Rivas, P.; Toro, M. Occurrence and Enumeration of Campylobacter spp. during the Processing of Chilean Broilers. BMC Microbiol. 2009, 9, 94. [CrossRef]

36. Ica, T.; Caner, V.; Istanbullu, O.; Nguyen, H.D.; Ahmed, B.; Call, D.R.; Beyenal, H. Characterization of Mono- and Mixed-Culture Campylobacter jejuni Biofilms. Appl. Environ. Microbiol. 2012, 78, 1033-1038. [CrossRef]

37. Fritts, C.A.; Kersey, J.H.; Motl, M.A.; Kroger, E.C.; Yan, F.; Si, J.; Jiang, Q.; Campos, M.M.; Waldroup, A.L.; Waldroup, P.W. Bacillus subtilis C-3102 (Calsporin) Improves Live Performance and Microbiological Status of Broiler Chickens. J. Appl. Poult. Res. 2000, 9 , 149-155. [CrossRef]

38. Guyard-Nicodeme, M.; Keita, A.; Quesne, S.; Amelot, M.; Poezevara, T.; Le Berre, B.; Sanchez, J.; Vesseur, P.; Martin, A.; Medel, P.; et al. Efficacy of Feed Additives against Campylobacter in Live Broilers during the Entire Rearing Period. Poult. Sci. 2016, 95, 298-305. [CrossRef]

39. Gracia, M.I.; Millan, C.; Sanchez, J.; Guyard-Nicodeme, M.; Mayot, J.; Carre, Y.; Csorbai, A.; Chemaly, M.; Medel, P. Efficacy of Feed Additives against Campylobacter in Live Broilers during the Entire Rearing Period: Part B. Poult. Sci. 2016, 95, 886-892. [CrossRef]

40. Harada, T.; Tokai, Y.; Kimura, A.; Ikeda, S.; Matsumura, M. Hydrolysis of Crystalline Cellulose to Glucose in an Autoclave Containing Both Gaseous and Liquid Water. RSC Adv. 2014, 4, 26838-26842. [CrossRef]

41. Manhar, A.K.; Bashir, Y.; Saikia, D.; Nath, D.; Gupta, K.; Konwar, B.K.; Kumar, R.; Namsa, N.D.; Mandal, M. Cellulolytic Potential of Probiotic Bacillus subtilis AMS6 Isolated from Traditional Fermented Soybean (Churpi): An in-Vitro Study with Regards to Application as an Animal Feed Additive. Microbiol. Res. 2016, 186-187, 62-70. [CrossRef] [PubMed]

42. Kim, Y.-K.; Lee, S.-C.; Cho, Y.-Y.; Oh, H.-J.; Ko, Y.H. Isolation of Cellulolytic Bacillus subtilis Strains from Agricultural Environments. ISRN Microbiol. 2012, 2012, 650563. [CrossRef] [PubMed] 
43. Mattossovich, R.; Iacono, R.; Cangiano, G.; Cobucci-Ponzano, B.; Isticato, R.; Moracci, M.; Ricca, E. Conversion of Xylan by Recyclable Spores of Bacillus subtilis Displaying Thermophilic Enzymes. Microbial. Cell Factories 2017, 16, 218. [CrossRef] [PubMed]

44. Méndez-Lorenzo, L.; Porras-Domínguez, J.R.; Raga-Carbajal, E.; Olvera, C.; Rodríguez-Alegría, M.E.; Carrillo-Nava, E.; Costas, M.; Munguía, A.L. Intrinsic Levanase Activity of Bacillus subtilis 168 Levansucrase (SacB). PLoS ONE 2015, 10, e0143394. [CrossRef]

45. Pan, D.; Yu, Z. Intestinal Microbiome of Poultry and Its Interaction with Host and Diet. Gut Microbes 2014, 5, 108-119. [CrossRef] [PubMed]

46. Cartman, S.T.; Ragione, R.M.L.; Woodward, M.J. Bacillus subtilis Spores Germinate in the Chicken Gastrointestinal Tract. Appl. Environ. Microbiol. 2008, 74, 5254-5258. [CrossRef] 